\title{
A CORRELATION STUDY OF THE DEVELOPMENTAL ROTATION
}

\author{
KUNIMITSU MORIYA \\ Department of Educational Psychology, Waseda University
}

\begin{abstract}
The developmental rotation means alternation among the developmental rhythms of functions. As the result of reviewing the past studies in the fields of developmental psychology, it seemed that the developmental rotation is an essential change in development. The previous studies centered around the rotation phenomenon in physical and motor development. This paper aimed, therefore, to find it out in the process of mental development. 658 normal infants served as $S$. The four tests were administered individually: Test 1 (Configuration), Test 2 (Judgment), Test 3 (Classification) and Test 4 (Memory). As a result, in the rotation period the correlations were low in general, while in the non-rotation period they were relatively high and tended to show oscilation.
\end{abstract}

The developmental rotation means alternation among the developmental rhythms of functions. As the result of reviewing the past studies in the fields of developmental psychology, it seemed that the developmental rotation is an essential change in development (Moriya, 1971). The previous studies centered around the rotation phenomenon in physical and motor development. This paper aimed, therefore, to find it out in the process of mental development.

\section{METHOD}

\section{Subjects}

Six hundred and fifty-eight normal infants (337 males and 321 females), living in Tokyo, with an age range of one year and eleven months $(1: 11)$ to six years and eleven months $(6: 11)$ served as subject.

\section{Instruments}

Out of the instruments, which are devised for predicting the level of development in young children (Moriya, 1970), the following three were used: a testing box $(28.5 \times 30.0 \times 27.5 \mathrm{~cm})$ with three colored-rectangle-holes $(0.5 \times 7.0 \mathrm{~cm})$ in the front; 48 right-angled equilateral triangle plastic boards $(5.5 \mathrm{~cm}$ each equilat- eral) in red, yellow, green and blue (16 each); and a life size face-shape with only a nose and hair printed on a paper.

\section{Procedure}

The four tests were administered individually according to the following procedure:

Test 1 (Configuration). The subject was instructed to complete the face-shape by placing several plastic boards in the position of eyes, ears and mouth. And then he was asked to discriminate right and left of the eyes and ears on the face-shape, and then of the subject's own hands and experimenter's hands.

Test 2 (Judgment). The subject was instructed to judge which of the two figures is larger or smaller. (These two figures were made of several plastic boards and were displayed on both sides, right and left, at the same time.) Then, the subject was asked the reason why he made his judgment.

Test 3 (Classification). The subject was instructed to put 48 plastic boards into three colored-rectangle-holes of the testing box, according to its color, as quickly as possible within the limited time of two 
Table 1

Derived score for each test

\begin{tabular}{|c|c|c|c|c|c|}
\hline \multirow{2}{*}{ Age level } & \multirow{2}{*}{$\begin{array}{c}\text { Numbers } \\
\text { of } \\
\text { subject }\end{array}$} & \multicolumn{4}{|c|}{ Derived score $(\%)$} \\
\hline & & $\begin{array}{c}\text { Test } 1 \\
\text { Configuration }\end{array}$ & $\begin{array}{c}\text { Test } 2 \\
\text { Judgment }\end{array}$ & $\begin{array}{c}\text { Test } 3 \\
\text { Classification }\end{array}$ & $\begin{array}{l}\text { Test } 4 \\
\text { Memory }\end{array}$ \\
\hline $1: 11-2: 3$ & 13 & 0.00 & 0.00 & 0.00 & 0.00 \\
\hline $2: 4-2: 7$ & 10 & 25.45 & 41.18 & -1.75 & 6.56 \\
\hline $2: 8-2: 11$ & 16 & 30.91 & 35.29 & 12.28 & 4.92 \\
\hline $3: 0-3: 1$ & 8 & 38.18 & 29.41 & 7.02 & 4.92 \\
\hline $3: 2-3: 3$ & 19 & 56.36 & 41.18 & 21.05 & 8.20 \\
\hline $3: 4-3: 5$ & 24 & 56.36 & 47.06 & 33.33 & 9.84 \\
\hline $3: 6-3: 7$ & 38 & 61.82 & 41.18 & 29.82 & 9.84 \\
\hline $3: 8-3: 9$ & 36 & 69.09 & 47.06 & 36.84 & 16.39 \\
\hline $3: 10-3: 11$ & 40 & 69.09 & 41.18 & 36.84 & 18.03 \\
\hline$+: 0-4: 1$ & 48 & 69.09 & 41.18 & 50.88 & 18.03 \\
\hline $4: 2-4: 3$ & 48 & 70.91 & 52.94 & 61.40 & 22.95 \\
\hline $4: 4-4: 5$ & 19 & 72.73 & 58.82 & 63.16 & 24.59 \\
\hline $4: 6-4: 7$ & 26 & 69.09 & 52.94 & 64.91 & 27.87 \\
\hline $4: 8-4: 9$ & 34 & 78.18 & 58.82 & 66.67 & 32.79 \\
\hline $4: 10-4: 11$ & 27 & 76.36 & 76.47 & 70.18 & 47.54 \\
\hline $5: 0-5: 1$ & 9 & 85.46 & 52.94 & 96.49 & 34.43 \\
\hline $5: 2-5: 3$ & 25 & 83.64 & 52.94 & 78.95 & 49.18 \\
\hline $5: 4-5: 5$ & 18 & 80.00 & 58.82 & 91.23 & 59.01 \\
\hline $5: 6-5: 7$ & 17 & 81.82 & 52.94 & 82.46 & 63.93 \\
\hline $5: 8-5: 9$ & 29 & 80.00 & 64.71 & 96.49 & 72.13 \\
\hline $5: 10-5: 11$ & 30 & 85.46 & 64.71 & 91.23 & 80.33 \\
\hline $6: 0-6: 1$ & 28 & 87.27 & 70.59 & 94.74 & 73.77 \\
\hline $6: 2-6: 3$ & 34 & 94.55 & 70.59 & 98.25 & 93.44 \\
\hline $6: 4-6: 5$ & 23 & 80.00 & 70.59 & 107.02 & 86.88 \\
\hline $6: 6-6: 7$ & 21 & 85.46 & 76.47 & 100.00 & 85.24 \\
\hline $6: 8-6: 9$ & 6 & 74.55 & 82.35 & 107.02 & 90.16 \\
\hline $6: 10-6: 11$ & 12 & 100.00 & 100.00 & 100.00 & 100,00 \\
\hline
\end{tabular}

Derived scores were calculated by the following formula:

$$
S_{a}=\frac{X_{l}-X_{l}}{X_{h_{l}}-X_{l}} \times 100
$$

where $S_{d}$ : derived score.

$X_{i}$ : mean score at each age level.

$X_{h}$ : mean score at the highest age level $(6: 10-6: 11)$.

$X_{l}$ : roean score at the lowest age level $(1: 11-2: 3)$.

minutes. The same trial was repeated four times. In the second trial, when he has put four plastic boards into the box, he was asked how many plastic boards he had put into the testing box; in the third trial, when he has put three plastic boards into the box, he was also asked how many boards he had put into the box; and in the fourth trial, when he has put five plastic boards into the box, he was asked how many boards he had put into the box. In this test the blue plastic boards were not 
employed because that color was not used on any hole of the box.

Test 4 (Memory). The subject was instructed to repeat backward a series of digits which he was told.

\section{Result}

The derived scores for each test were calculated referring to the mean score in each age level for direct comparative purpose. They are shown in Table 1 . The developmental curve for each test was plotted in Fig. 1 to Fig. 6 with these derived scores. In order to compare directly each developmental curve, they were plotted in pairs in the same figure.

Fig. 1 suggests a small tendency of the rotation period around the center in the former half $(3: 0-5: 0)$ between Test 1 (Configuration) and Test 2 (Judgment). Fig. 2 suggests the period of rotation around the center $(4: 10-6: 4)$ between

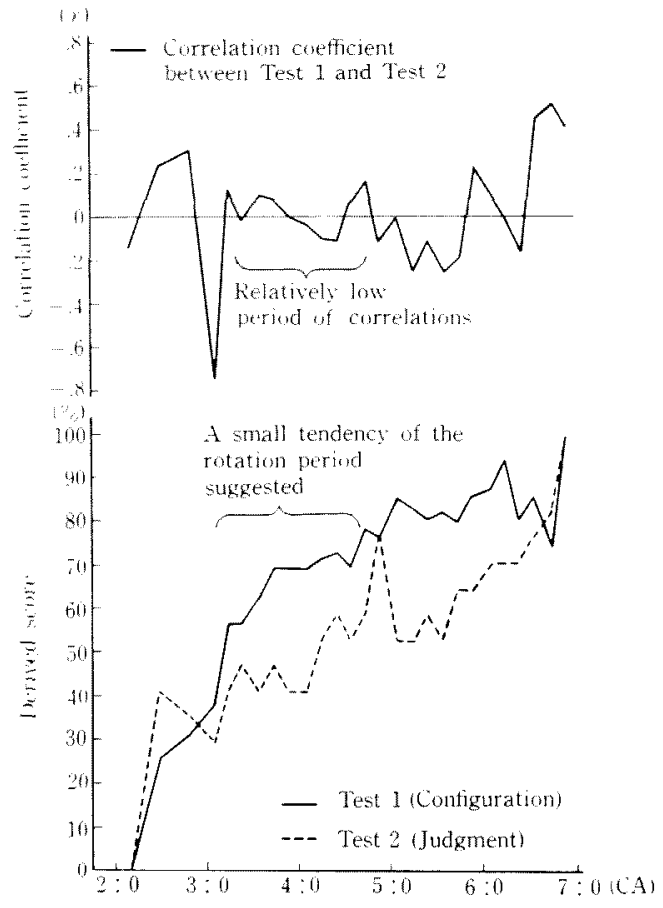

Fig. 1. Developmental curves: Derived scores and correlations (Test 1 and Test 2).
Test 1 and Test 3 (Classification). Fig. 3 suggests the rotation period in the last quarter $(5: 8-6: 8)$ between Test 1 and Test 4 (Memory). Fig. 4 shows clearly the period of rotation around the center (3: 10-5:0) between Test 2 and Test 3 . Fig. 5 suggests the period of rotation around the center in the latter half (5:26:11) between Test 2 and Test 4 . Fig. 6 shows no clear period of rotation between Test 3 and Test 4.

Table 2 shows the results of correlation coefficients between tests. These correlations between tests were calculated referring to individuals. In order to match the change of correlations with the rotation period suggested by the direct comparison of developmental curves with derived scores, these correlation coefficients were plotted in the same figure of the developmental curves with derived scores.

Comparing the change of correlations with the period of rotation suggested, there

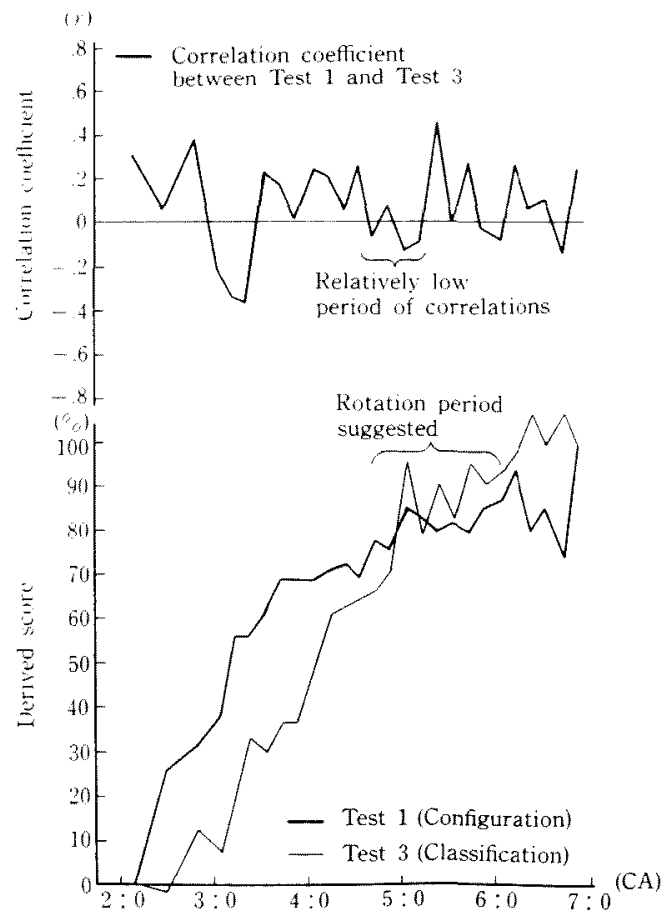

Fig. 2. Developmental curves: Derived scores and correlations (Test 1 and Test 3 ). 


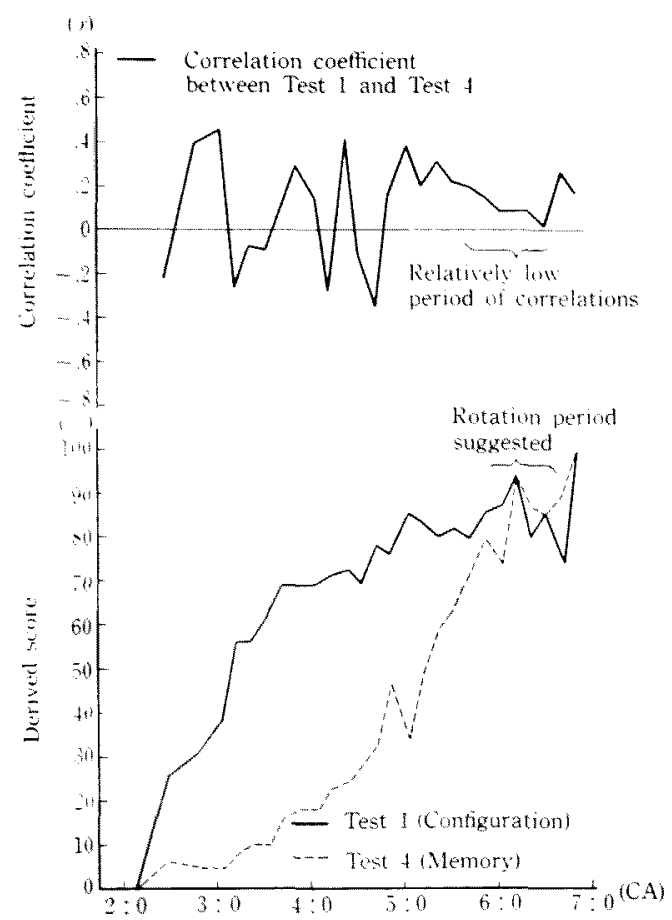

FIg. 3. Developmental curves: Derived scores and correlations (Test 1 and Test 4 ).

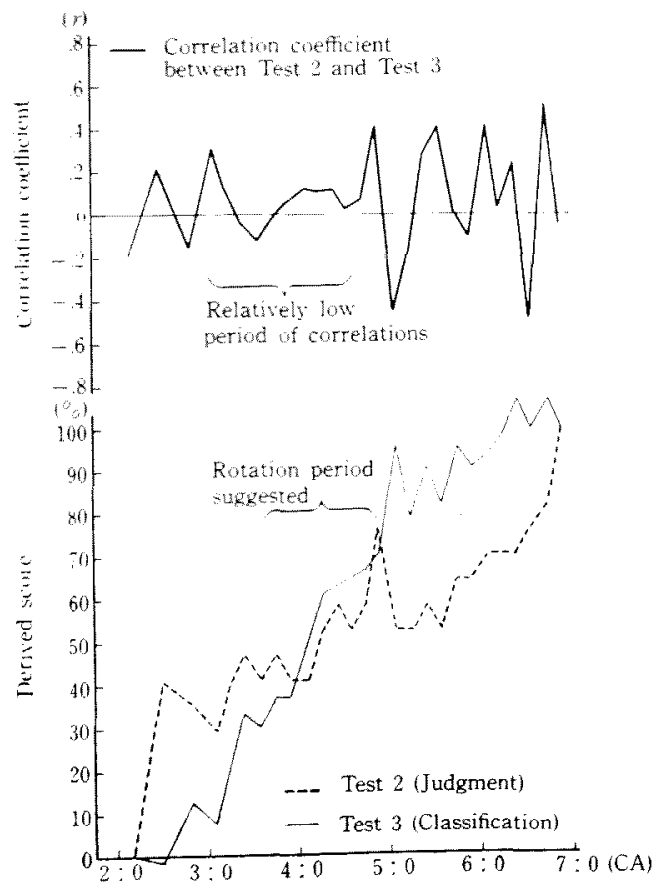

Fig. 4. Developmental curves: Derived scores and correlations (Test 2 and Test 3 ).

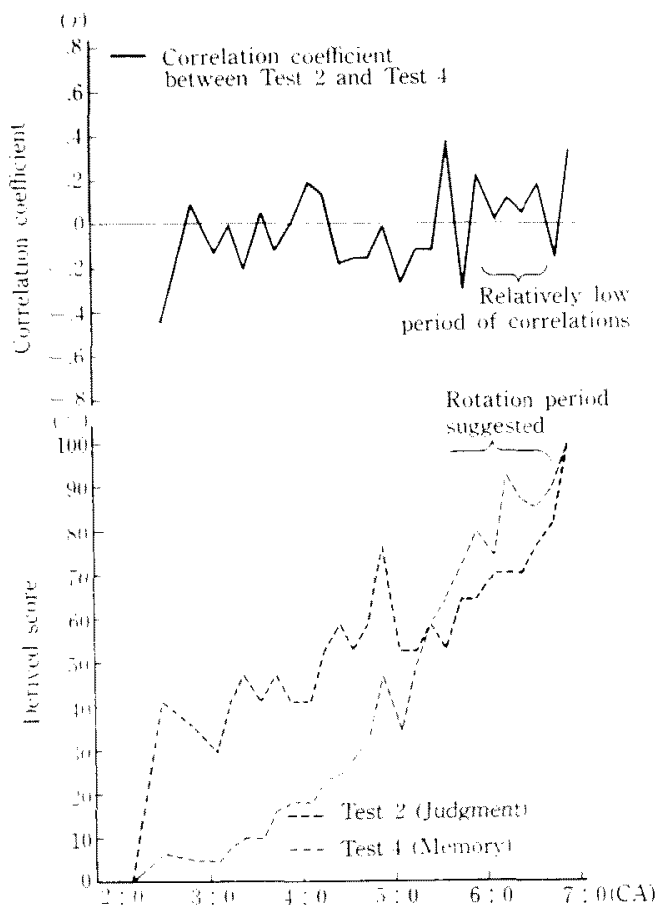

Fig. 5. Developmental curves: Derived scores and correlations (Test 2 and Test 4 ).

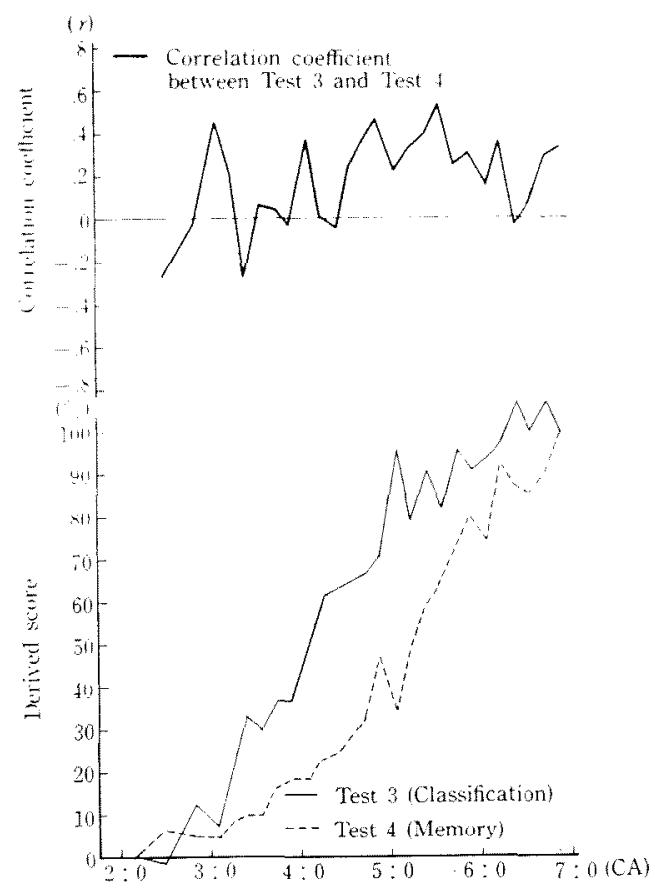

Fig. 6. Developmental curves: Derived sores and correlations (Test 3 and Test 4 ). 
TABLE 2

Correlation coefficient

\begin{tabular}{|c|c|c|c|c|c|c|}
\hline \multirow[b]{2}{*}{ Age level } & \multicolumn{6}{|c|}{ Correlation coefficient } \\
\hline & $\begin{array}{l}\text { Between } \\
\text { test } 1 \text { and } \\
\text { test } 2\end{array}$ & $\begin{array}{l}\text { Between } \\
\text { test } 1 \text { and } \\
\text { test } 3\end{array}$ & $\begin{array}{l}\text { Between } \\
\text { test } 1 \text { and } \\
\text { test } 4\end{array}$ & $\begin{array}{l}\text { Between } \\
\text { test } 2 \text { and } \\
\text { test } 3\end{array}$ & $\begin{array}{l}\text { Between } \\
\text { test } 2 \text { and } \\
\text { test } 4\end{array}$ & $\begin{array}{l}\text { Between } \\
\text { test } 3 \text { and } \\
\text { test } 4\end{array}$ \\
\hline $1: 11-2: 3$ & -.133 & .306 & & -.178 & & \\
\hline $2: 4-2: 7$ & .250 & .059 & -.207 & .234 & -.470 & -.283 \\
\hline $2: 8-2: 11$ & .319 & .383 & .402 & -.143 & .079 & -.043 \\
\hline $3: 0-3: 1$ & $-.738^{*}$ & -.211 & .472 & .333 & -.149 & .448 \\
\hline $3: 2-3: 3$ & .146 & -.346 & -.252 & .128 & -.016 & .208 \\
\hline $3: 4-3: 5$ & -.005 & -.372 & -.064 & -.024 & -.221 & -.285 \\
\hline $3: 6-3: 7$ & .108 & .227 & -.085 & -.108 & .044 & .066 \\
\hline $3: 8-3: 9$ & .096 & .164 & .116 & -.013 & -.130 & .046 \\
\hline $3: 10-3: 11$ & .015 & .014 & .299 & .070 & -.013 & -.032 \\
\hline $4: 0-4: 1$ & -.034 & .243 & .144 & .137 & .178 & $.371 * *$ \\
\hline $4: 2-4: 3$ & -.082 & .213 & -.278 & .120 & .135 & .002 \\
\hline $4: 4-4: 5$ & -.095 & .059 & .435 & .137 & -.193 & -.052 \\
\hline $4: 6-4: 7$ & .077 & .260 & -.104 & .037 & -.162 & .234 \\
\hline $4: 8-4: 9$ & .178 & -.066 & $-.353^{*}$ & .080 & -.173 & $.359 *$ \\
\hline $4: 10-4: 11$ & -.107 & .086 & .166 & $.433^{*}$ & -.015 & $.463 *$ \\
\hline $5: 0-5: 1$ & .000 & -.132 & .396 & -.443 & -.283 & .214 \\
\hline $5: 2-5: 3$ & -.258 & -.093 & .206 & -.166 & -.128 & .317 \\
\hline $5: 4-5: 5$ & -.101 & .458 & .322 & .294 & -.129 & .384 \\
\hline $5: 6-5: 7$ & -.249 & .001 & .233 & .424 & .372 & $.528^{*}$ \\
\hline $5: 8-5: 9$ & -.182 & .269 & .201 & .031 & -.312 & .245 \\
\hline $5: 10-5: 11$ & .230 & -.028 & .163 & -.089 & .219 & .294 \\
\hline $6: 0-6: 1$ & .099 & -.081 & .095 & $.437 *$ & .023 & .151 \\
\hline $6: 2-6: 3$ & -.001 & .263 & .096 & .033 & .109 & $.356^{*}$ \\
\hline $6: 4-6: 5$ & -.164 & .068 & .092 & .252 & .046 & -.047 \\
\hline $6: 6-6: 7$ & $.460^{*}$ & .103 & .017 & $-.488^{*}$ & .185 & .071 \\
\hline $6: 8-6: 9$ & .523 & -.140 & .274 & .536 & -.174 & .280 \\
\hline $6: 10-6: 11$ & .425 & .245 & .175 & -.040 & .320 & .322 \\
\hline
\end{tabular}

is a tendency between the correlations and the rotation period. That is, in the period of rotation the correlations are low in general, and in the non-rotation period they are relatively high and tend to show oscilation.

In this study, the rotation period does not always occur at the same time in all pairs of developmental curves. In other words, its appearing period differs according to the kind of pair. Indeed, between Test 3 and Test 4 no clear period of rota- tion appears.

\section{References}

Moriya, K. 1970 Standardizing of the mental development test for young children: A study of developmental morphology in young children. Unpublished master's thesis, Waseda University (in Japanese).

Moriya, K. 1971 A discussion of the biological model of developmental rotation. Fournal of Child Development, 7, 35-47.

(Received Dec. 28, 1972) 